\title{
Beneficial Applications and Deleterious Effects of Near-Infrared from Biological and Medical Perspectives
}

\author{
Yohei Tanaka, Lisa Gale \\ Clinica Tanaka Plastic, Reconstructive Surgery and Anti-Aging Center, Matsumoto, Japan \\ Email: info@clinicatanaka.jp
}

Received April 23, 2013; revised May 29, 2013; accepted June 20, 2013

Copyright (c) 2013 Yohei Tanaka, Lisa Gale. This is an open access article distributed under the Creative Commons Attribution License, which permits unrestricted use, distribution, and reproduction in any medium, provided the original work is properly cited.

\begin{abstract}
Over half of solar energy consists of near-infrared and a wide range of preventative mechanisms have been evolutionarily maintained in organisms to protect against effects of near-infrared. However, the biological effects of near-infrared have not been investigated in detail. Despite the essential requirement of a water-filter to imitate solar near-infrared filtered by atmospheric water, previous studies used near-infrared resources without a water-filter or a cooling system. With these methods, near-infrared energy is primarily absorbed in the superficial tissues, thus these approaches are unable to sufficiently evaluate the biological effects of solar near-infrared that reaches human tissue. We have elucidated that near-infrared (1100 - $1800 \mathrm{~nm}$ together with a water-filter that excludes wavelengths $1400-1500 \mathrm{~nm})$ non-thermally affects the skin into the deeper tissues. The biological effects of near-infrared have both beneficial applications and deleterious effects. Near-infrared induces collagen and elastin stimulation, which achieves skin rejuvenation and skin tightening, and induces long-lasting vasodilation that may prevent vasospasm and be beneficial for ischemic disorders. Near-infrared also relaxes and weakens dystonic and hypertrophic muscles to reduce wrinkles and myalgia. Nearinfrared is an essential tool in cancer detection and imaging, and induces drastic non-thermal DNA damage of mitotic cells, which may be beneficial for treating cancer. Activation of stem cells by near-infrared may be useful in regenerative medicine. However, continuous near-infrared exposure induces photoaging and potentially photocarcinogenesis. Humans have protective mechanisms against near-infrared on multiple levels, including perspiration, blisters, vasodilation, hair, skin, adipose tissue, and cotton or wool clothing. Further protection should be considered, as biological effects of near-infrared are significant, and standard sunscreens and glasses cannot sufficiently block near-infrared. This paper reviews the effects of near-infrared and introduces the new findings of near-infrared from a biological point of view.
\end{abstract}

Keywords: Biological Effects; Near-Infrared; Non-Thermal; Water-Filter

\section{Introduction}

Previous studies regarding near-infrared (NIR) have described its applications in the industrial and agricultural fields. In medicine, the biological effects of sun and ultraviolet (UV) exposure have been extensively investigated. However, although over half of the solar energy is NIR, the biological effects of NIR and its specific effects on human tissue have not been well investigated [1-3].

Despite the wide prevalence of a variety of UV blocking materials, such as sunblock, sunglasses, films, and fibers, that are useful in protecting skin against UV exposure, NIR cannot be blocked. Consequently, NIR can induce undesirable photoaging $[1,2,4]$, long-lasting vasodilation [5], long-lasting muscle thinning [6,7], sagging and skin ptosis $[1,2,4]$, and potentially photocarcino- genesis $[1,2,4]$.

It has not been well recognized that a water-filter is indispensable to experimentally simulate the solar NIR that reaches the skin [1], as solar NIR is filtered by atmospheric water $[8,9]$. A contact cooling is also recommended for investigation of the properties of solar NIR, as NIR increases the surface temperature and induces thermal effects [1].

We previously determined that NIR between 1100 $1800 \mathrm{~nm}$ together with a water-filter that excludes wavelengths between 1400 - $1500 \mathrm{~nm}$ penetrates deep into human tissue and is absorbed by water in the skin [10], hemoglobin in dilated vessels [5], myoglobin [6,7], and hydrogen bonds in lamin and DNA [1,2,4], and is scattered by adipose cells [11]. NIR exhibits both wave and particle properties, possesses high permeability, and can in- 
duce various biological effects [1-4].

NIR can stimulate wound healing [12-14] and treat malignant tumors [15-18]. NIR can also achieve skin rejuvenation and skin tightening [19-21], induce long-lasting vasodilation that is beneficial for ischemic disorders [5], and relax and weaken dystonic and hypertrophic muscles to reduce wrinkles and myalgia [6,7]. In addition to usefulness in cancer detection and imaging, NIR induction of DNA damage in cancer cells should be investigated further for an effective cancer treatment [22,23]. NIR can also activate stem cells, which may be beneficial in regenerative medicine [2].

On the other hand, NIR will easily penetrate deeper and damage human tissue in fair skin with a thin dermis compared to darker skin with a thick dermis $[1,2]$. As human skin is exposed to tremendous amounts of both solar and artificial NIR from medical devices and electrical appliances [24,25], and most sunscreens, sunglasses and glasses cannot block NIR [1,2,4], thus sunscreens and glasses should be equipped with protection ability against not only UV but also NIR [1,2,4,24-28].

Demand for transparent materials for NIR blocking will increase as the biological effects of NIR become more widely known. However, supply of these materials may not be sufficient.

Unfortunately, the beneficial applications of NIR and the necessity to protect against NIR have not been well recognized. Further studies are needed to more closely evaluate the biological effects of NIR that have both potentially beneficial applications and detrimental effects.

\section{Methods to Investigate Biological Effects of Solar NIR}

Incident solar energy is composed of $6.8 \% \mathrm{UV}$ light, $38.9 \%$ visible light, and 54.3\% NIR [29], and NIR is filtered by atmospheric water $[8,9]$. Solar NIR wavelengths above $2500 \mathrm{~nm}$ are completely filtered by atmospheric water and cannot be delivered to the Earth at sea level. The peak wavelengths of solar NIR are $500-600 \mathrm{~nm}$, which is different from NIR of incandescent filament lamps whose wavelengths include NIR and mid-wavelength IR, with peak wavelengths $800-1500 \mathrm{~nm}$.

Notably, NIR devices using an incandescent filament lamp emitting wide wavelengths of NIR without a water filter or contact cooling were used in previous studies [12, 30-32]. With these methods, NIR immediately increases the temperature of the superficial layer of culture fluid in a laboratory dish or skin, as NIR is predominantly absorbed by hydrogen bond-containing molecules, such as water and hemoglobin. The energy of NIR then decreases as it penetrates deeper, and will not reach enough target cells in the base or deeper tissues. Therefore, previous reports were only able to describe the superficial and thermal effects of NIR, and the experimental designs were not appropriate to examine the biological effects of NIR [1,2].

Wavelengths below $1100 \mathrm{~nm}$ will be absorbed by melanin in the skin, and wavelengths between 1400 and $1500 \mathrm{~nm}$ and those above $1850 \mathrm{~nm}$ will be absorbed by water in the skin, which results in heating and possible induction of painful sensations and burns [17]. To imitate the incident solar NIR and deliver NIR energy to the deeper tissues, filtering out the wavelengths below 1100 $\mathrm{nm}$, around $1450 \mathrm{~nm}$, and above $1850 \mathrm{~nm}$ is essential [33].

NIR increases the surface temperature and induces thermal effects, thus, to reduce the skin surface temperature, perspiration, and blood vessel dilation, contact cooling is recommended.

To accurately investigate the biological effects of solar NIR, a water-filter that excludes wavelengths between 1400 and $1500 \mathrm{~nm}$ and the cooling system are indispensable.

\section{Discussion}

\subsection{The Evolutionary History of Protective Mechanisms against NIR}

When life first originated on the Earth, the first forms of life appeared in water and thus did not need to adapt to dehydration, gravity, UV or NIR as the surrounding water served as a barrier against these obstacles. The need to overcome these obstacles arose for the first time when primitive life developed on land. Every species of terrestrial life has acquired fibrous structural proteins rich in hydrogen bonds and alpha helices: cellulose for plants, fibrous chitin and proteins for insects, and keratin for reptiles, birds, amphibians, and mammals. These components are biologically-economical, practical and beneficial to overcome the obstacles.

The fibrous structural proteins rich in hydrogen bonds and alpha helices are particularly convenient for NIR blocking because hydrogen bonds and alpha helices efficiently absorb NIR. For instance, sheep prefer the sun to the shade, and even though the animals remain in sunny environments without much perspiration, their body temperature does not become elevated, as sheep wool consists of alpha helical structures that efficiently block and absorb NIR.

Humans have acquired protective mechanisms against NIR on multiple levels, including perspiration, vasodilation, hair, skin, adipose tissue, and wearing cotton or wool, which are all rich in hydrogen bonds and alpha helices [Figure 1].

NIR induces perspiration to increase water retention superficially and decrease superficial temperature, and subsequently induces vasodilation to increase water and hemoglobin retention as a NIR absorbent. In the dermis, 


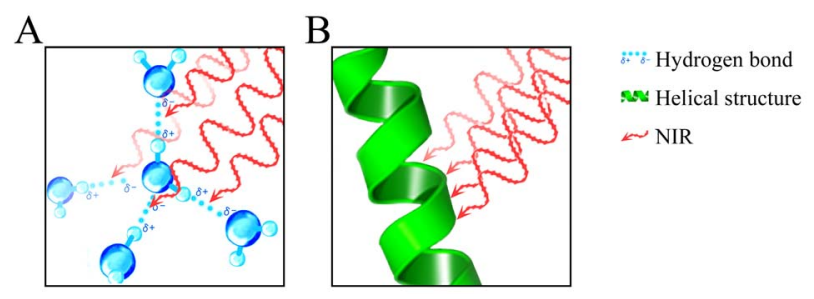

Figure 1. A schematic of NIR's chromophore. (A) NIR exhibits both wave and particle properties and is absorbed by hydrogen bonds among water molecules in perspiration, vasodilation, and the dermis; (B) NIR is also absorbed by helical structures of hemoglobin, myoglobin, keratin, collagen, and elastin.

NIR induces accumulation of collagen, elastin and waterbinding proteins, which possess helical structures rich in hydrogen bonds $[1,2,4]$. Over the long-term, NIR induces subcutaneous adipocytes located above superficial muscles, which are effective for NIR blocking, because adipose tissue can scatter NIR optically [11].

The effects of NIR are independent of generated heat [12]. NIR non-thermally induces degeneration of myoglobin, resulting in apoptosis of vascular smooth muscle cells and long-lasting vasodilation [Tanaka]. Our collagen, elastin, and cancer studies suggest that NIR may mainly resonate hydrogen bonds, helical structures, alpha helices, and DNA [1,2,4]. Alpha helices are thought to be resonated by NIR [34]. Both hemoglobin and myoglobin are oxygen-carrying proteins with many hydrogen bonds and alpha helices. It is possible that NIR induces resonance of helical structures in the oxygen-carrying proteins and degenerates proteins containing hydrogen bonds and helical structures, which results in damage to the storage and transport of oxygen. This could be one of the mechanisms of apoptosis [1,2].

In addition to the skin, the optic nerve, which is the only exposed component of the central nervous system, also has protective mechanisms against NIR on multiple levels. These mechanisms include rich blood flow in the retina, hyaluronic acid in the lens, tears in sclera, and adipose tissue in the eyelid. These are effective protective mechanisms, as water, hemoglobin, and fatty acid are all ideal materials rich in hydrogen bonds and alpha helices for blocking NIR exposure [2].

\subsection{Molecular Biological Responses to NIR}

NIR exhibits both wave and particle properties and appears to resonate hydrogen bonds and alpha helices [Figure 1], and therefore can affect the deeper tissues and induce various biological effects. The NIR spectrum is a result of the overtones and combination of bond stretching vibrations from $\mathrm{O}-\mathrm{H}, \mathrm{C}-\mathrm{H}$, and $\mathrm{N}-\mathrm{H}$ groups [35].

Humans have biological protective mechanisms against NIR that absorb NIR by induction of substances rich in hydrogen bonds and alpha helices, or reflect NIR by induction of fatty acid to protect the subcutaneous tissues against NIR [1,2]. NIR is absorbed by water in perspiration and blisters, hemoglobin and water in vasodilation, keratin in hair and the horny layer of the skin, and water-binding proteins and water in the dermis, and is reflected by adipose tissue [Figure 1].

The cell nucleus possesses a nuclear lamina underneath the inner nuclear membrane. The nuclear lamina contains lamins, which have a conserved alpha helical central rod domain and variable head and tail domains [36-38], that form a stress-resistant elastic network [36]. Lamins play important roles in DNA replication, chromatin organization, adult stem cell differentiation, aging, and tumorigenesis. In addition, mutations in lamin lead to laminopathic diseases [36]. Nuclei assembled in the absence of lamins are more prone to breakage than nuclei assembled in the presence of a full complement of lamins $[39,40]$. Disruption of lamins results in abnormal mitosis, chromosomal segregation, and cell death [41]. Thus, lamins absorb NIR and protect DNA in the nucleus from NIR [1] [Figure 2].

During mitosis, lamin molecules are transiently disassembled into monomers [42,43]. NIR induces non-thermal DNA damage of mitotic cells in prophase, metaphase, and anaphase due to the absence of nuclear lamin protection against NIR, which results in apoptotic cell death [1]. This could be one of the mechanisms of apoptosis in cancer [1].

Further studies are required to fully investigate the biological responses to NIR in humans.

\subsection{Beneficial Effects of NIR}

NIR induces dermal heating and induces collagen and elastin stimulation, resulting in skin tightening $[10,19$, $44,45]$. NIR induces high collagen density in the dermis, leading to epidermal smoothness without scar formation, which provides safe, consistent, and long-term effects of skin rejuvenation [20,21]. Pre-exposure of NIR prevents UV-induced toxicity $[30,46,47]$, and this effect is independent of heat shock protein induction and cell division [47]. These findings support the hypothesis that NIR prepares skin to better resist the subsequent damage from UV or NIR [1].

NIR can treat musculoskeletal disorders and healing of indolent wounds [48,49]. NIR induces long-lasting vasodilation for an increase in blood circulation by causing apoptosis of vascular smooth muscle cells, which may prevent vasospasm and may be beneficial for ischemic disorders [2]. NIR activates mitochondrial metabolism [50-53], assists wound healing, and promotes angiogenesis in skin [54], bone [55], nerve [56], and skeletal muscle $[57,58]$. NIR also relaxes and weakens dystonic or hypertrophic muscles to reduce wrinkles and myalgia. 


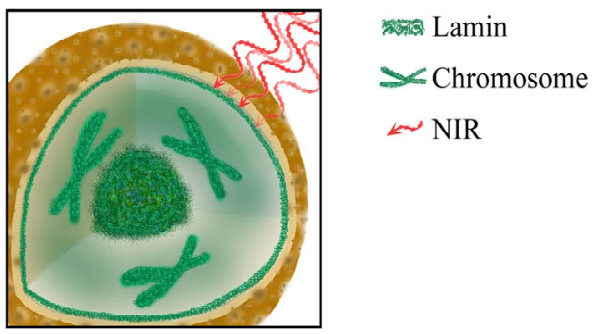

Figure 2. A schematic of NIR and lamin in the nucleus. Lamins absorb NIR and protect DNA in the nucleus from NIR.

Thus, the simple technique of using NIR may offer an alternative method to relax superficial muscles [7].

We previously reported that NIR increased subcutaneous adipocytes on the superficial muscles as well as CD34-positive stem cells surrounding the subcutaneous adipocytes, which may have an application for volume augmentation [11]. Further, NIR increased subcutaneous and bone marrow adipocytes and CD34-positive hematopoietic stem cells in bone marrow, and cortical bone mass [11]. Stimulation of stem cells by NIR might be beneficial for applications in regenerative medicine [2].

NIR is also an essential tool in cancer detection and imaging, as actively proliferating cells show increased sensitivity to NIR [59,60].

The most common anti-tumor therapy using NIR is photodynamic therapy (PDT) based on the accumulation of a photosensitizer in tumors, which is effective for some forms of cancer [61]. PDT uses wavelengths near $800 \mathrm{~nm}$ as a photoactivating wavelength to achieve maximum penetration depth [62], but this wavelength also has high melanin absorption, limiting the ability to deliver light to highly pigmented tumors [63]. Shorter wavelengths are the standard activators for PDT but other wavelengths have shown treatment promises. NIR at a wavelength of $904 \mathrm{~nm}$ has anti-tumor activity and increases cytomorphological changes by inducing apoptosis in neoplastic cells [64]. In addition, actively proliferating cells show increased sensitivity to NIR $[59,60]$. NIR induces DNA strand breaks and cell death by apoptosis [65], eliciting photodisruptive destruction of tumor tissue [66]. Unlike wavelengths beyond $1100 \mathrm{~nm}$ where melanin absorption is negligible [8], absorption at 904 $\mathrm{nm}$ is significant. This may limit possible uses of the 904 $\mathrm{nm}$ wavelength for certain body areas in races with skin rich in melanin $[4,22,23]$.

NIR from 1100 to $1800 \mathrm{~nm}$ together with a water-filter that excludes wavelengths between 1400 and $1500 \mathrm{~nm}$ induces non-thermal DNA damage of mitotic cells particularly in prophase, metaphase, and anaphase due to the absence of nuclear lamin protection [1], and suppresses the proliferation of various kinds of malignant cells [22, 23]. While NIR damages tumor tissue, it is also shown to reduce cellular protein damage produced by biological oxidants in normal cells [67].

NIR may be beneficial in multiple fields of medicine, as the schedule reduces discomfort and side effects, deep subcutaneous tissues are accessible, and the approach enables repeated irradiations [2].

As NIR has a very wide range of wavelengths, the wavelength or fluence should be investigated, in order to induce beneficial effects without deleterious effects. Further, conditions and parameters should be also evaluated, as higher output, increased frequency of treatments, and/ or longer periods of irradiation may induce deleterious effects.

These findings indicate that NIR has a wide range of biological effects, and future studies are warranted to develop these findings into beneficial techniques and applications.

\subsection{Deleterious Effects of NIR}

NIR performs as an aging factor, where biological NIR protection is not complete. NIR induces photoaging similar to that observed in solar elastosis, and enhances UVinduced dermal damage [32]. NIR activates mitogen-activated protein kinases and induces gene transcription, and appears to increase collagen degradation [24,25,68].

Long-term exposure to sources of heat and NIR, such as fires and stoves, results in erythema abigne [69], which is characterized by a reticular hyperpigmentation and telangiectasia accompanied by epidermal atrophy, vasodilation, dermal melanin and hemosiderin deposits [1]. Longterm exposure of NIR from various heat sources is thought to induce reticulated erythema and result in histopathological changes similar to those seen in solar-damaged skin [70]. The occurrence of telangiectasia appeared to increase with age, increased sunbathing, and poor pigmentation ability [71].

Similar to UV, NIR induces photoaging and potentially photocarcinogenesis [24]. In addition, skin tumors appeared faster after irradiation with the full lamp spectrum containing UV, visible, and NIR compared to irradiation with UV alone [72]. NIR induces non-thermal DNA damage and drastic cell death of mitotic cancer cells, and cancer stem cells might be activated to maintain homeostasis.

NIR is attenuated by thick water-containing dermis. Thus, skin with a thin dermis allows NIR to penetrate deeper into tissue than skin with a thick dermis [1]. The mean area of the facial surface covered with wrinkles is significantly larger in Caucasians than in African Americans, and characteristics of age-related periorbital changes seem to occur at a more accelerated rate in Caucasians [73]. In addition, fair skin is more sensitive to skin aging $[74,75]$. These findings support the observation that fair skin tends to wrinkle and sag earlier in life [76,77], as 
fair skin is thinner and more susceptible to NIR damage to the underlying superficial muscles than dark skin [1].

Continual long-term exposure to solar NIR causes superficial muscle thinning, which ultimately leads to skin ptosis [6]. Although further studies are required to confirm our results, these results may have major implications in superficial tissue aging and skin ptosis.

NIR produces clouding of the cornea and cataract, as NIR is easily absorbed by the anterior segment, such as the cornea, aqueous, and lens [78-80].

As over half of the solar energy is NIR and biological effects of NIR are significant, NIR protection should be performed on multiple levels, including perspiration, vasodilation, hair, skin, adipose tissue, sunblock, sunglasses, films, and clothing.

\subsection{Materials for NIR Block}

Hints of effective NIR blocking are hidden in the evolutionary history of life. Every species of terrestrial life has acquired fibrous structural proteins, such as cellulose, chitin, and keratin during evolution. These substances rich in helical structures and hydrogen bonds are biologically-economical, practical and, beneficial to block NIR.

Humans have been naturally protected from NIR by perspiration, keratin, hemoglobin, water-binding proteins, such as collagen, and elastin, and by using clothing made from biological NIR blocking materials, such as cellulose and keratin. Removing hair and the horny layer of the skin decreases protection abilities against NIR.

Other than the biological materials for NIR block, metal oxides such as titanium oxide, zinc oxide, compounds containing silicon, and organic compounds are common in the industrial field. They can block both thermal and non-thermal effects of NIR. NIR is also emitted from monitors, screens, and electrical appliances, so materials for NIR block often require transparency.

Demand for transparent materials for NIR blocking is and will be increasing as the biological effects of NIR become widely known. However, supply of these materials may not be sufficient. A common transparent material for blocking NIR is compounds containing indium, though its supply is limited due to various factors, such as scarcity and environmental constraint. Alternatives to indium should be developed and are urgently required.

A variety of light and heat blocking materials, such as sunblock, sunglasses, films, and fibers, should equip protection ability against not only UV but also NIR, and should be widely prevalent for prevention against aging and carcinogenesis.

\section{Conclusions}

The biological effects of NIR have both beneficial appli- cations and deleterious effects.

NIRinduces dermal heating and non-thermally induces collagen and elastin stimulation, which achieves skin rejuvenation and skin tightening, and induces long-lasting vasodilation that may prevent vasospasm and may be beneficial for ischemic disorders. NIR also non-thermally relaxes and weakens dystonic and hypertrophic muscles to reduce wrinkles and myalgia. NIR is an essential tool in cancer detection and imaging, and induces non-thermal DNA damage of mitotic cells, which may have the potential application for treating cancer. Its activation of stem cells may be beneficial in regenerative medicine. New techniques using NIR should prove to be beneficial in many fields of medicine.

Continuous NIR may cause unexpected photoaging, muscle thinning and stimulation of stem cells, including cancer stem cells, in areas of the body exposed to the sun. Protection against NIR should be considered, as standard UV blocking materials cannot sufficiently block NIR. The development of effective materials for NIR blocking is urgently required.

Although the potential of NIR is significant, the range of its applications in the medical field has not been well known. Additional non-thermal studies using a water filter and contact cooling are needed to more accurately investigate the biological effects of NIR in humans.

\section{REFERENCES}

[1] Y. Tanaka, "Impact of Near-Infrared in Dermatology, Review,” World Journal of Dermatology, Vol. 1, No. 3, 2012, pp. 30-37.

http://www.wjgnet.com/2218-6190/full/v1/i3/30.htm

[2] Y. Tanaka, Y. Tunemi, M. Kawashima and H. Nishida, “The Impact of Near-Infrared in Plastic Surgery,” Plastic Surgery: An International Journal, 2013, Article ID 973073. doi:10.5171/2013.973073

[3] Y. Tanaka and M. Kawashima, "The Biological Effects of Near-Infrared,” Aesthetic Dermatology, Vol. 22, 2012, pp. 100-109 (in Japanese).

[4] Y. Tanaka and K. Matsuo, "Non-Thermal Effects of NearInfrared Irradiation on Melanoma,” In: Y. Tanaka, Ed., Breakthroughs in Melanoma Research, InTech, Croatia, 2011, pp. 597-628.

http://www.intechopen.com/books/breakthroughs-in-mela noma-research/non-thermal-effects-of-near-infrared-irradi ation-on-melanoma

[5] Y. Tanaka, K. Matsuo and S. Yuzuriha, "Near-Infrared Irradiation Non-Thermally Induces Long-Lasting Vasodilation by Causing Apoptosis of Vascular Smooth Muscle Cells,” ePlasty, Vol. 11, 2011, p. e22.

http://www.eplasty.com/index.php?option=com_content \&view=article\&id=541\&catid=172:volume-11-eplasty-20 11

[6] Y. Tanaka, K. Matsuo and S. Yuzuriha, "Long-Lasting Muscle Thinning Induced by Infrared Irradiation Special- 
ized with Wavelength and Contact Cooling: A Preliminary Report," ePlasty, Vol. 10, 2010, p. e40. http://www.eplasty.com/index.php?option=com_content \&view=article\&id=453\&catid=171:volume-10-eplasty-20 10

[7] Y. Tanaka, K. Matsuo and S. Yuzuriha, "Long-Lasting Relaxation of Corrugator Supercilii Muscle Contraction Induced by Near Infrared Irradiation,” ePlasty, Vol. 11, 2011, p. e6.

http://www.eplasty.com/index.php?option=com_content \&view=article\&id=519\&catid=172:volume-11-eplasty-20 11

[8] R. R. Anderson and J. A. Parrish, "The Optics of Human Skin,” Journal of Investigative Dermatology, Vol. 77, No. 1, 1981, pp. 13-19. doi:10.1111/1523-1747.ep12479191

[9] D. M. Gates, "Spectral Distribution of Solar Radiation at the Earth's Surface,” Science, Vol. 151, No. 3710, 1966, pp. 523-529. doi:10.1126/science.151.3710.523

[10] Y. Tanaka, K. Matsuo and S. Yuzuriha, "Long-Term Evaluation of Collagen and Elastin Following Infrared (1100 to $1800 \mathrm{~nm}$ ) Irradiation," Journal of Drugs in Dermatology, Vol. 8, No. 8, 2009, pp. 708-712.

[11] Y. Tanaka, K. Matsuo and S. Yuzuriha, "Near-Infrared Irradiation Non-Thermally Affects Subcutaneous Adipocytes and Bones,” ePlasty, Vol. 11, 2011, p. e12. http://www.eplasty.com/index.php?option=com_content \&view=article\&id=528\&catid=172:volume-11-eplasty-20 11

[12] K. Danno, N. Mori, K. Toda, T. Kobayashi and A. Utani, "Near-Infrared Irradiation Stimulates Cutaneous Wound Repair: Laboratory Experiments on Possible Mechanisms," Photodermatology, Photoimmunology \& Photomedicine, Vol. 17, No. 6, 2001, pp. 261-265. doi:10.1034/j.1600-0781.2001.170603.x

[13] L. R. Horwitz, T. J. Burke and D. Carnegie, “Augmentation of Wound Healing Using Monochromatic Infrared Energy. Exploration of a New Technology for Wound Management," Advances in Skin \& Wound Care, Vol. 12, No. 1, 1999, pp. 35-40.

[14] J. M. Schramm, D. Warner, R. A. Hardesty and K. C. Oberg, "A Unique Combination of Infrared and Microwave Radiation Accelerates Wound Healing," Plastic and Reconstructive Surgery, Vol. 111, No. 1, 2003, pp. 258266. doi:10.1097/00006534-200301000-00044

[15] W. Bäumler, C. Abels, S. Karrer, T. Weiss, H. Messmann, M. Landthaler and R. M. Szeimies, "Photo-Oxidative Killing of Human Colonic Cancer Cells Using Indocyanine Green and Infrared Light,” British Journal of Cancer, Vol. 80, No. 3-4, 1999, pp. 360-363. doi:10.1038/sj.bjc.6690363

[16] C. Dees, J. Harkins, M. G. Petersen, W. G. Fisher and E. A. Wachter, "Treatment of Murine Cutaneous Melanoma with Near Infrared Light," Photochemistry and Photobiology, Vol. 75, No. 3, 2002, pp. 296-301. doi:10.1562/0031-8655(2002)075<0296:TOMCMW>2.0. $\mathrm{CO} ; 2$

[17] D. K. Kelleher, O. Thews, J. Rzeznik, A. Scherz, Y. Salomon and P. Vaupel, "Hot Topic. Water-Filtered Infrared -A Radiation: A Novel Technique for Localized Hyper- thermia in Combination with Bacteriochlorophyll-Based Photodynamic Therapy,” International Journal of Hyperthermia, Vol. 15, No. 6, 1999, pp. 467-474. doi:10.1080/026567399285468

[18] A. Orenstein, G. Kostenich, Y. Kopolovic, T. Babushkina and Z. Malik, "Enhancement of ALA-PDT Damage by IR-Induced Hyperthermia on a Colon Carcinoma Model," Photochemistry and Photobiology, Vol. 69, No. 6, 1999, pp. 703-707.

[19] Y. Tanaka, K. Matsuo, S. Yuzuriha and H. Shinohara, "Differential Long-Term Stimulation of Type I versus Type III Collagen after Infrared Irradiation,” Dermatologic Surgery, Vol. 35, No. 7, 2009, pp. 1099-1104. doi:10.1111/j.1524-4725.2009.01194.X

[20] Y. Tanaka, K. Matsuo and S. Yuzuriha, "Long-Term Histological Comparison between Near-Infrared Irradiated Skin and Scar Tissues," Clinical, Cosmetic and Investigational Dermatology, Vol. 3, No. 1, 2010, pp. 143-149. http://www.dovepress.com/articles.php?article_id=5752

[21] Y. Tanaka, K. Matsuo and S. Yuzuriha, “Objective Assessment of Skin Rejuvenation Using Near-Infrared 1064nm Neodymium: YAG Laser in Asians,” Clinical, Cosmetic and Investigational Dermatology, Vol. 4, No. 1, 2011, pp. 123-130.

http://www.dovepress.com/articles.php?article_id=7972

[22] Y. Tanaka, K. Matsuo, S. Yuzuriha, H. Yan and J. Nakayama, "Non-Thermal Cytocidal Effect of Infrared Irradiation on Cultured Cancer Cells Using Specialized Device,” Cancer Science, Vol. 101, No. 6, 2010, pp. 1396-1402. doi:10.1111/j.1349-7006.2010.01548.x

[23] Y. Tanaka, N. Tatewaki, H. Nishida, T. Eitsuka, N. Ikekawa and J. Nakayama, "Non-Thermal DNA Damage of Cancer Cells Using Near-Infrared Irradiation," Cancer Science, Vol. 103, No. 8, 2012, pp. 1467-1473. doi:10.1111/j.1349-7006.2012.02310.x

[24] S. M. Schieke, P. Schroeder and J. Krutmann, "Review Article. Cutaneous Effects of Infrared Radiation: From Clinical Observations to Molecular Response Mechanisms,” Photodermatology, Photoimmunology \& Photomedicine, Vol. 19. No. 5, 2003, pp. 228-234. doi:10.1034/j.1600-0781.2003.00054.x

[25] P. Schroeder, J. Lademann, M. E. Darvin, H. Stege, C. Marks, S. Bruhnke and J. Krutmann, "Infrared RadiationInduced Matrix Metalloproteinase in Human Skin: Implications for Protection," Journal of Investigative Dermatology, Vol. 128, No. 10, 2008, pp. 2491-2497. doi:10.1038/jid.2008.116

[26] M. E. Darvin, S. Haag, M. Meinke, L. Zastrow, W. Sterry and J. Lademann, "Radical Production by Infrared A Irradiation in Human Tissue," Skin Pharmacology and Physiology, Vol. 23, No. 1, 2010, pp. 40-46. doi:10.1159/000257262

[27] M. C. Meinke, S. F. Haag, S. Schanzer, N. Groth, I. Gersonde and J. Lademann, "Radical Protection by Sunscreens in the Infrared Spectral Range,” Photochemistry and Photobiology, Vol. 87, No. 2, 2011, pp. 452-456. doi:10.1111/j.1751-1097.2010.00838.x

[28] J. A. Pujol and M. Lecha, "Photoprotection in the Infrared Radiation Range,” Photodermatology, Photoimmunology 
\& Photomedicine, Vol. 9, 1993, pp. 275-278.

[29] I. E. Kochevar, M. A. Pathak and J. A. Parrish, "Photophysics, Photochemistry and Photobiology,” In: I. M. Freedberg, A. Z. Eisen, K. Wolff, K. F. Austen, L. A. Goldsmith and S. I. Katz, Eds., Fitzpatrick's Dermatology in General Medicine, McGraw-Hill, New York, 1999, pp. 220-229.

[30] S. Frank, L. Oliver, C. Lebreton-De Coster, C. Moreau, M. T. Lecabellec, L. Michel, F. M. Vallette, L. Dubertret and B. Coulomb, "Infrared Radiation Affects the Mitochondrial Pathway of Apoptosis in Human Fibroblasts," Journal of Investigative Dermatology, Vol. 123, No. 5, 2004, pp. 823-831. doi:10.1111/j.0022-202X.2004.23472.x

[31] H. H. Kim, M. J. Lee, S. R. Lee, K. H. Kim, K. H. Cho, H. C. Eun and J. H. Chung, "Augmentation of UV-Induced Skin Wrinkling by Infrared Irradiation in Hairless Mice,” Mechanisms of Ageing and Development, Vol. 126, No. 11, 2005, pp. 1170-1177. doi:10.1016/j.mad.2005.06.003

[32] L. H. Kligman, "Intensification of Ultraviolet-Induced Dermal Damage by Infrared Radiation,” Archives of Dermatological Research, Vol. 272, No. 3-4, 1982, pp. 229238. doi:10.1007/BF00509050

[33] S. A. Davenport, D. A. Gollnick, M. Levernier and G. J. R. Spooner, "Method and System for Treatment of PostPartum Abdominal Skin Redundancy or Laxity," US Patent No. 20060052847, 2006.

[34] N. A. Nevskaya and Y. N. Chirgadze, "Infrared Spectra and Resonance Interactions of Amide-I and II Vibrations of Alpha-Helix,” Biopolymers, Vol. 15, No. 4, 1976, pp. 637-648. doi:10.1002/bip.1976.360150404

[35] L. G. Weyer, "Near-Infrared Spectroscopy of Organic Substances,” Applied Spectroscopy Reviews, Vol. 21, No. 1-2, 1985, pp. 1-43. doi:10.1080/05704928508060427

[36] M. Prokocimer, M. Davidovich, M. Nissim-Rafinia, N. Wiesel-Motiuk, D. Z. Bar, R. Barkan, E. Meshorer and Y. Gruenbaum, "Nuclear Lamins: Key Regulators of Nuclear Structure and Activities," Journal of Cellular and Molecular Medicine, Vol. 13, No. 6, 2009, pp. 1059-1085. doi:10.1111/j.1582-4934.2008.00676.x

[37] N. Stuurman, S. Heins and U. Aebi, "Nuclear Lamins: Their Structure, Assembly, and Interactions," Journal of Structural Biology, Vol. 122, No. 1-2, 1998, pp. 42-66. doi:10.1006/jsbi.1998.3987

[38] M. Zaremba-Czogalla, M. Dubinska-Magiera and R. Rzepecki, "Laminopathies: The Molecular Background of the Disease and the Prospects for Its Treatment," Cellular \& Molecular Biology Letters, Vol. 16, No. 1, 2011, pp. 114-148. doi:10.2478/s11658-010-0038-9

[39] T. Sullivan, D. Escalante-Alcalde, H. Bhatt, M. Anver, N. Bhat, K. Nagashima, C. L. Stewart and B. Burke, "Loss of A-Type Lamin Expression Compromises Nuclear Envelope Integrity Leading to Muscular Dystrophy," The Journal of Cell Biology, Vol. 147, No. 5, 1999, pp. 913920. doi:10.1083/jcb.147.5.913

[40] J. W. Newport, K. L. Wilson and W. G. Dunphy, “A Lamin-Independent Pathway for Nuclear Envelope Assembly," The Journal of Cell Biology, Vol. 111, No. 6,
1990, pp. 2247-2259. doi:10.1083/jcb.111.6.2247

[41] J. Liu, K. K. Lee, M. Segura-Totten, K. L. Wilson and Y. Gruenbaum, "MAN1 and Emerin Have Overlapping Function(s) Essential for Chromosome Segregation and Cell Division in Caenorhabditis Elegans," Proceedings of the National Academy of Sciences of the United States of America, Vol. 100, No. 8, 2003, pp. 4598-4603.

[42] L. Gerace and G. Blobel, "The Nuclear Envelope Lamina Is Reversibly Depolymerised during Mitosis,” Cell, Vol. 19, No. 1, 1980, pp. 277-287. doi:10.1016/0092-8674(80)90409-2

[43] L. Yang, T. Guan and L. Gerace, "Integral Membrane Proteins of the Nuclear Envelope Are Dispersed throughout the Endoplasmic Reticulum during Mitosis," The Journal of Cell Biology, Vol. 37, No. 6, 1997, 1199-1210.

[44] D. J. Goldberg, M. Hussain, A. Fazeli and A. L. Berlin, "Treatment of Skin Laxity of the Lower Face and Neck in Older Individuals with a Broad Spectrum Infrared Light Device," Journal of Cosmetic and Laser Therapy, Vol. 9, No. 1, 2007, pp. 35-40. doi:10.1080/14764170601186107

[45] B. Zelickson, V. Ross, D. Kist, J. Counters, S. Davenport and G. Spooner, "Ultrastructural Effects of an Infrared Handpiece on Forehead and Abdominal Skin,” Dermatologic Surgery, Vol. 32, No. 7, 2006, pp. 897-901. doi:10.1111/j.1524-4725.2006.32193.x

[46] K. Danno, T. Horio and S. Imamura, "Infrared Radiation Suppresses Ultraviolet B-Induced Sunburn-Cell Formation," Archives of Dermatological Research, Vol. 284, No. 2, 1992, pp. 92-94. doi:10.1007/BF00373376

[47] S. Menezes, B. Coulomb, C. Lebreton and L. Dubertret, "Non-Coherent near Infrared Radiation Protects Normal Human Dermal Fibroblasts from Solar Ultraviolet Toxicity,” Journal of Investigative Dermatology, Vol. 111, 1998, pp. 629-633. doi:10.1046/j.1523-1747.1998.00338.x

[48] Y. Ceylan, S. Hizmetli and Y. Siling, "The Effects of Infrared Laser and Medical Treatments on Pain and Serotonin Degradation Products in Patients with Myofascial Pain Syndrome: A Controlled Trial,” Rheumatology International, Vol. 24, No. 5, 2003, pp. 260-263. doi:10.1007/s00296-003-0348-6

[49] C. Webb, M. Dyson and W. H. Lewis, "Stimulatory Effect of 660 nm Low Level Laser Energy on Hypertrophic Scar-Derived Fibroblasts: Possible Mechanisms for Increase in Cell Counts," Lasers in Surgery and Medicine, Vol. 22, No. 5, 1998, pp. 294-301. doi:10.1002/(SICI)1096-9101(1998)22:5<294::AID-LSM 6>3.0.CO;2-K

[50] T. Karu, "Invited Review. Primary and Secondary Mechanisms of Action of Visible to Near-IR Radiation on Cells,” Journal of Photochemistry and Photobiology B: Biology, Vol. 49, No. 1, 1999, pp. 1-17. doi:10.1016/S1011-1344(98)00219-X

[51] S. Passarella, E. Casamassima, S. Molinari, D. Pastore, E. Quagliariello, I. M. Catalano and A. Cingolani, "Increase of Proton Electrochemical Potential and ATP Synthesis in Rat Liver Mitochondria Irradiated in Vitro by HeliumNeon Laser,” FEBS Letters, Vol. 175, No. 1, 1984, pp. 95-99. doi:10.1016/0014-5793(84)80577-3 
[52] W. Yu, J. O. Naim, M. McGowan, K. Ippolito and R. J. Lanzafame, "Photomodulation of Oxidative Metabolism and Electron Chain Enzymes in Rat Liver Mitochondria," Photochemistry and Photobiology, Vol. 66, No. 6, 1997, pp. 866-871. doi:10.1111/j.1751-1097.1997.tb03239.x

[53] L. Wilden and R. Karthein, "Import of Radiation Phenomena of Electrons and Therapeutic Low-Level Laser in Regard to the Mitochondrial Energy Transfer,” Journal of Clinical Laser Medicine \& Surgery, Vol. 16, No. 3, 1998, pp. 159-165.

[54] M. J. Conlan, J. W. Rapley and C. M. Cobb, "Biostimulation of Wound Healing by Low-Energy Laser Irradiation,” Journal of Clinical Periodontology, Vol. 23, No. 5, 1996, pp. 492-496. doi:10.1111/j.1600-051X.1996.tb00580.x

[55] T. Yaakobi, L. Maltz and U. Oron, "Promotion of Bone Repair in the Cortical Bone of the Tibia in Rats by Low Energy Laser (He-Ne) Irradiation,” Calcified Tissue International, Vol. 59, No. 4, 1996, pp. 297-300. doi:10.1007/s002239900126

[56] E. Assia, M. Rosner, M. Belkin, A. Solomon and M. Schwartz, "Temporal Parameters of Low Energy Laser Irradiation for Optimal Delay of Post-Traumatic Degeneration of Rat Optic Nerve,” Brain Research, Vol. 476, No. 2, 1989, pp. 205-212. doi:10.1016/0006-8993(89)91240-7

[57] A. Bibikova and U. Oron, "Attenuation of the Process of Muscle Regeneration in the Toad Gastrocnemius Muscle by Low Energy Laser Irradiation,” Lasers in Surgery and Medicine, Vol. 14, No. 4, 1994, pp. 355-361. doi:10.1002/lsm.1900140408

[58] U. Oron, "Photoengineering of Tissue Repair in Skeletal and Cardiac Muscles," Photomedicine and Laser Surgery, Vol. 24, No. 2, 2006, pp. 111-120. doi:10.1089/pho.2006.24.111

[59] T. Karu, L. Pyatibrat and G. Kalendo, "Irradiation with He-Ne Laser Can Influence the Cytotoxic Response of HeLa Cells to Ionizing Radiation,” International Journal of Radiation Biology, Vol. 65, No. 6, 1994, pp. 691-697. doi:10.1080/09553009414550811

[60] J. Tafur and P. J. Mills, "Low-Intensity Light Therapy: Exploring the Role of Redox Mechanisms," Photomedicine and Laser Surgery, Vol. 26, No. 4, 2008, pp. 321326. doi:10.1089/pho.2007.2184

[61] T. J. Dougherty, C. J. Gomer, B. W. Henderson, G. Jori, D. Kessel, M. Korbelik, J. Moan and Q. Peng, " Photodynamic Therapy,” Journal of the National Cancer Institute, Vol. 90, No. 12, 1998, pp. 889-905. doi:10.1093/jnci/90.12.889

[62] J. Lobel, I. J. MacDonald, M. J. Ciesielski, T. Barone, W. R. Potter, J. Pollina, R. J. Plunkett, R. A. Fenstermaker and T. J. Dougherty, "2-(1-Hexyloxyethyl)-2-devinylpyropheophorbide-a (HPPH) in a Nude Rat Glioma Model: Implications for Photodynamic Therapy," Lasers in Surgery and Medicine, Vol. 29, No. 5, 2001, pp. 397-405. doi:10.1002/lsm.10001

[63] A. Busetti, M. Soncin, G. Jori, M. E. Kenney and M. A. Rodgers, "Treatment of Malignant Melanoma by HighPeak-Power 1064 nm Irradiation Followed by Photody- namic Therapy,” Photochemistry and Photobiology, Vol. 68, No. 3, 1998, pp. 377-381.

doi:10.1111/j.1751-1097.1998.tb09695.x

[64] L. A. Santana-Blank, E. Rodriguez-Santana, F. Vargas, H. Reyes, P. Fernandez-Andrade, S. Rukos and K. E. Santana-Rodriguez, "Phase I Trial of an Infrared Pulsed Laser Device in Patients with Advanced Neoplasias," Clinical Cancer Research, Vol. 8, No. 10, 2002, pp. 30823091.

[65] U. K. Tirlapur and K. König, "Femtosecond Near-Infrared Laser Pulse Induced Strand Breaks in Mammalian Cells," Cell and Molecular Biology, Vol. 47, 2001, pp. 131-134.

[66] C. Dees, J. Harkins, M. G. Petersen, W. G. Fisher and E. A. Wachter, "Treatment of Murine Cutaneous Melanoma with near Infrared Light," Photochemistry and Photobiology, Vol. 75, No. 3, 2002, pp.296-301.

doi:10.1562/0031-8655(2002)075<0296:TOMCMW>2.0. $\mathrm{CO} ; 2$

[67] J. Kujawa, I. B. Zavodnik, A. Lapshina, M. Labieniec and M. Bryszewska, "Cell Survival, DNA, and Protein Damage in B14 Cells under Low-Intensity Near-Infrared (810nm) Laser Irradiation,” Photomedicine and Laser Surgery, Vol. 22, No. 6, 2004, pp. 504-508. doi:10.1089/pho.2004.22.504

[68] M. S. Kim, Y. K. Kim, K. H. Cho and J. H. Chung, "Infrared Exposure Induces an Angiogenic Switch in Human Skin that Is Partially Mediated by Heat,” British Journal of Dermatology, Vol. 155, No. 6, 2006, pp. 11311138. doi:10.1111/j.1365-2133.2006.07510.x

[69] G. R. Findlayson, W. M. Sams Jr. and J. G. Smith, "Erythema Ab Igne. A Histopathological Study,” The Journal of Investigative Dermatology, Vol. 46, 1966, pp. 104-107.

[70] E. H. Page and N. H. Shear, "Temperature-Dependent Skin Disorders," Journal of the American Academy of Dermatology, Vol. 18, No. 5, 1988, pp. 1003-1019. doi:10.1016/S0190-9622(88)70098-5

[71] M. Berg, "Epidemiological Studies of Influence of Sunlight on the Skin,” Photo-Dermatology, Vol. 6, No. 2, 1989, pp. 80-84.

[72] J. A. Bain, H. P. Rusch and B. E. Kline, “The Effect of Temperature upon Ultraviolet Carcinogenesis with Wavelength 2,800-3,400A," Cancer Research, Vol. 3, 1943, pp. 610-612.

[73] M. Odunze, D. S. Rosenberg and J. W. Few, “Periorbital Aging and Ethnic Considerations: A Focus on Leteral Canthal Complex," Plastic \& Reconstructive Surgery, Vol. 121, No. 3, 2008, pp. 1002-1008. doi:10.1097/01.prs.0000299381.40232.79

[74] C. Guinot, D. J. Malvy, L. Ambroisine, J. Latreille, E. Mauger, M. Tenenhaus, F. Morizot, S. Lopez, I. LeFur and E. Tschachler, "Relative Contribution of Intrinsic vs. Extrinsic Factors to Skin Aging as Determined by a Validated Skin Age Score," Archives of Dermatology, Vol. 138, No. 11, 2002, pp. 1454-1460.

doi:10.1001/archderm.138.11.1454

[75] H. Nagashima, K. Hanada and I. Hashimoto, "Correlation of Skin Phototype with Facial Wrinkle Formation," 
Photodermatology, Photoimmunology \& Photomedicine, Vol. 15, 1999, pp. 2-6.

doi:10.1111/j.1600-0781.1999.tb00044.x

[76] A. V. Rawlings, "Ethnic Skin Types: Are There Differences in Skin Structure and Function? Review Article, ” International Journal of Cosmetic Science, Vol. 28, No. 2, 2006, pp. 79-93. doi:10.1111/j.1467-2494.2006.00302.X

[77] T. Tsukahara, T. Fujimura, Y. Yoshida, T. Kitahara, M. Hotta, S. Moriwaki, P. S. Witt, F. A. Simion and Y. Takema, "Comparison of Age-Related Changes in Wrinkling and Sagging of the Skin in Caucasian Females and in Japanese Females," Journal of Cosmetic Science, Vol. 55, No. 4, 2004, pp. 373-385.
[78] E. M. Aly and E. S. Mohamed, "Effect of Infrared Radiation on the Lens," Indian Journal of Ophthalmology, Vol. 59, No. 2, 2011, pp. 97-101. doi:10.4103/0301-4738.77010

[79] E. Lydahl, "Infrared Radiation and Cataract," Acta Ophthalmologica. Supplementum, Vol. 166, 1984, pp. 163.

[80] M. M. Zaret, W. Z. Snyder and L. Birenbaum, "Cataract after Exposure to Non-Ionizing Radiant Energy,” British Journal of Ophthalmology, Vol. 60, No. 9, 1976, pp. 632-637. doi:10.1136/bjo.60.9.632 